\title{
Posttraumatic facial nerve regeneration in rabbits.
}

\section{Heloisa Juliana Zabeu Rossi Costa ${ }^{1}$, Ciro Ferreira da Silva', Gustavo Polacow Korn ${ }^{3}$,Paulo Roberto Lazarini}

Keywords: rabbits, nerve, facial, regeneration.

\section{Summary}

\begin{abstract}
$\mathrm{P}$ the facial paralysis is a frequent disease. This work studies posttraumatic regeneration of the facial nerve in rabbits. Functional and histological analysis compared injured and normal nerves on opposite sides. The left facial nerve trunk of twenty rabbits were subjectedto compression lesion, and sacrificed after two (subgroup AL), four (BL) and six (CL) weeks. Comparison between groups was made by analysing total and partial densities of myelinated axons. Statistical analysis: Tukey Method $(\mathrm{p} \leq 0.05)$. Results: There was partial functional recovery after two weeks, and complete recovery after five weeks. Qualitative analysis demonstrated a degenerative pattern in the AL group, with an increased tissue inflammatory process. Evident regeneration signs were observed in the BL group, and almost complete regeneration was seen in the CL group. Normal nerves (N) had an average TD of 15705.59 and average PD of 21800.75 . The BL group had an average TD of 10818.55 and an average PD of 15340.56. The CL group had an average TD of 13920.36 and an average PD of 16589.15 . The BL group had an average TD of $\mathrm{N}$ equal to $68.88 \%$, and the CL group had an average TD of $\mathrm{N}$ equal to $88,63 \%$ (statistically significant). $\mathrm{N}$ showed a significant higher PD than injured nerves. However, this was not statistically different between BL and CL subgroups. Nerve DT was a more reliable method than PD in this study.
\end{abstract}

\footnotetext{
${ }^{1}$ ENT specialist, recognized by the Brazilian ENT Society (SBORL); Master in ENT, trained at the Sao Paulo Santa Casa Medical College; Doctoral student at the ENT Department of the Sao Paulo Santa Casa Medical College; Assistant Professor at the USP Medical School University Hospital. ${ }^{2}$ Lecturing Professor at the Sao Paulo University Biomedical Science College.$$
{ }^{3} \text { M.S. Student - Department of ENT/HNS - Federal University of São Paulo. }
$$

${ }^{4}$ Doctor in Otorhinolaryngology, trained at the Sao Paulo Univeersity Medical College, Assistant professor of the Otorhinolaryngology Unit of the Sao Paulo Santa Casa de Misericordia; graduate professor at the Santa Casa Medical Science College in Sao Paulo. Sao Paulo Santa Casa.

Correspondence: Heloisa Juliana Zabeu Rossi Costa - Rua Gabriel dos Santos 759 120. andar Higienópolis São Paulo SP 01231-011 Telephone: (0xx11) 3825-5946/9964-1683

The CNPq (Conselho Nacional de Desenvolvimento Cientifico e Tecnologico) Brazil (proc. 131879/2001-4) and the Fundo de Amparo a Pesquisa da Fundacao Arnaldo Vieira de Carvalho.

Paper submitted to the ABORL-CCF SGP (Management Publications System) on May 11th, 2005 and accepted for publication on June 2th, 2006. cod. 309.
} 


\section{INTRODUCTION}

Traumatic peripheral facial palsy (TPFP) is currently a frequent condition due to the increasing number of motor vehicle accidents, personal injury collisions and bullet wounds. ${ }^{1-4}$

Treatment for complete facial nerve severing has improved with the development of microsurgical nerve repair techniques. Incomplete nerve injury, however, is treated medically and depends on the research for new drugs and methods to aid the nerve regeneration process. ${ }^{5}$

There are many methodological studies aiming to find the most adequate model for the experimental research of systemically used substances which could act on post-traumatic facial nerve regeneration (animal species, injury site and method, progression time, and histological and functional analysis methods).

There is a standardized experimental model for peripheral nerve research which uses the rat sciatic nerve. ${ }^{6-12}$ The facial nerve, however, does not respond to repair like peripheral nerves. ${ }^{13-19}$

It is relevant to specifically study facial nerve regeneration, and not only to transpose peripheral nerve research results to injuries of this cranial nerve. There are no published studies counting the number of facial nerve trunk myelinated neurons in rabbits to assess nerve regeneration.

The aim of this trial was to study post-traumatic facial nerve regeneration in rabbits by the functional assessment of face movements and qualitative and quantitative histological analysis of the injured facial nerve compared to the normal facial nerve.

\section{MATERIAL AND METHODS}

This study was submitted to and approved by the Research Ethics Committee for procedures in experimental animals at the Sao Paulo Santa Casa, protocol \# 69

Compression injury was done on the left extratemporal facial nerve trunk in 20 young adult male New Zealand rabbits weighing on average $2,000 \mathrm{~g}(1,800$ to $2,500 \mathrm{~g}$ ). After 2,4 and 6 weeks following injury, the animals were sacrificed and the extratemporal facial nerve trunk was resected bilaterally for histological studies. The distal segment of the injured nerve (subgroup L) and the non-injured contralateral nerve (subgroup N) were analyzed in each animal.

We obtained the following groups for analysis:

$\mathrm{N}=$ normal, obtained after two, four and six weeks;

$\mathrm{AL}=$ injured, obtained after two weeks;

$\mathrm{BL}=$ injured obtained after four weeks;

$\mathrm{CL}=$ injured, obtained after six weeks.

Animals were anesthetized with intramuscular Zoletil@ (tiletamine chloridrate, zolazepan chloridrate,
$0,4 \mathrm{mg} / \mathrm{kg}$ ) and Inoval@ (fentanyl citrate and droperidol, $0.3 \mathrm{mg} / \mathrm{kg}$ ).

Tricotomy of the cervical region was followed by antisepsis and asepsis. An arciform skin incision was made on the left cervical region, from the mastoid process to the mid-region of the mandible, followed by surgical nerve exploration in the anatomical space between the mandibular arch and the mastoid process (Figures $1 \mathrm{a}$ and $1 \mathrm{~b}$ ).

After isolating the extratemporal facial nerve trunk, compression injury was done approximately $0.2 \mathrm{~cm}$ below the nerve emergence from the stylomastoid foramen using a microsurgical forceps (Dietrich bulldog clamp - Codman ( - 150g prehension force). The cross-sectional nerve crush forceps position was maintained for 60 seconds. ${ }^{5}$

Animals were kept in individual cages and given standard ration and water ad libitum in adequate environmental conditions.

After 2, 4 or 6 weeks following nerve injury, the facial nerve was resected for histological studies and the animals were sacrificed. Anesthesia and the initial steps of nerve exploration used the same technique employed during the nerve crush. The nerve was fixated in situ in the deeply anesthetized live animal with glutaraldehyde $2 \%$ and paraformaldehyde $1 \%$, and buffered with a sodium phosphate buffer at 0.1 molar and $\mathrm{pH}=7.3$. Animals were sacrificed using an intracardiac injection of potassium chloride, followed by removal of the nerve segment from the crush site until $0.5 \mathrm{~cm}$ distal from this site (the distal end of the fragment was beveled for identification).

The material was post-fixated in osmium $2 \%$, dehydrated (gradual ethanol baths), infiltrated with propylene oxide and included in Epoxi@ resin until polymerization. Sections $1 \mathrm{~m}$ thick were stained toluidine blue $1 \%$.

\section{Histological study}

Histology was done by optic microscopy using a Nikon model Eclipse E 600 microscope. Slides were photographed with a Nikon Coolpix E 955 model digital camera, recorded on a CD and transported to a computer. The specific cell counting program Sigma Scan Pro 5.0 program was used.

Qualitative analysis included the following parameters: general nerve architecture, tissue organization pattern and degree of remyelinization.

Quantitative analysis included the number of injured facial nerve myelin fibers distal to the crush site and the number of contralateral normal facial nerve myelin fibers. Analysis was as follows: a) a total count of the number of axons; b) a count of axons per field ( 4 homogeneous fields at $1,000 \mathrm{X})$; c) measurement of the total nerve crosssectional area; d) measurement of the partial nerve crosssectional area (4 fields at 1,000X).

Quantitative histology values were used to calculate the total axon density (total number of axons divided by 


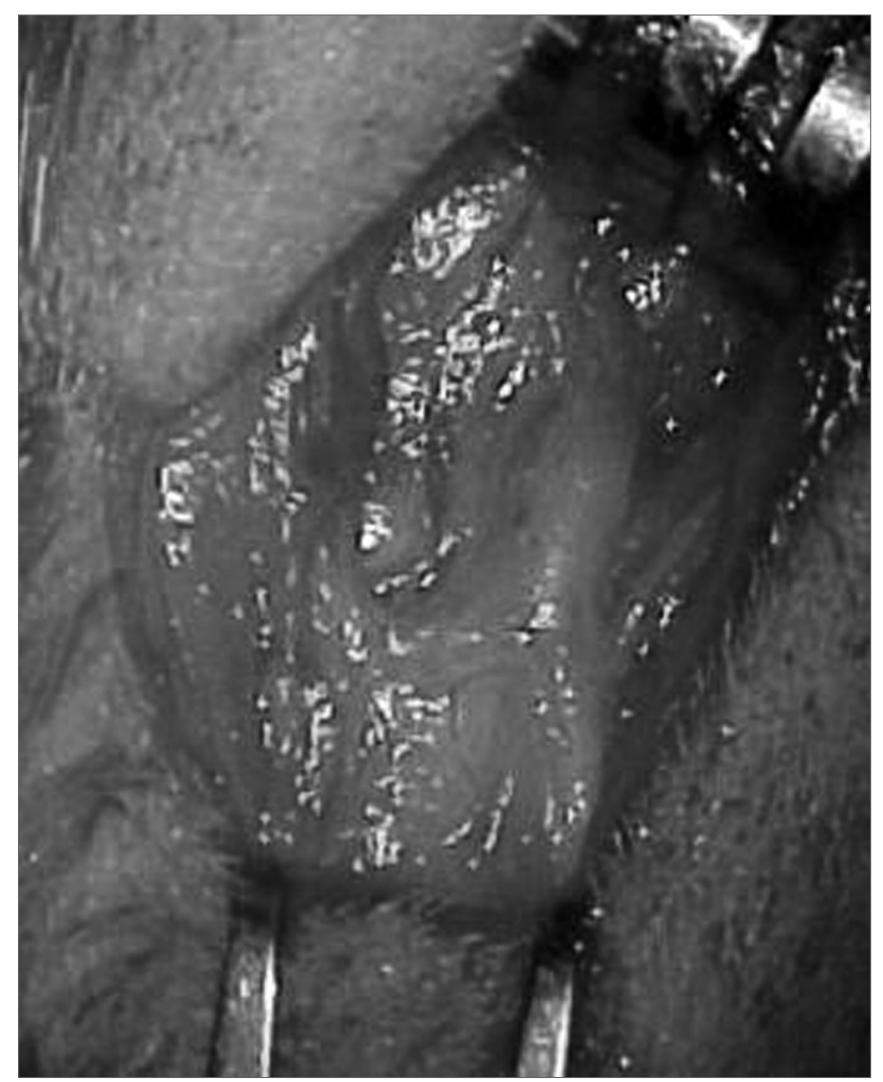

Figure 1a. Left extratemporal facial nerve trunk in the rabbit.

the total nerve cross-sectional area), and the partial axon density (axons per field divided by the partial nerve crosssectional area).

\section{Assessment of function}

Clinical assessment was according to the weekly method used by Jones (1993).20 The following parameters were observed: facial muscle tonicity and movement, blinking reflex and vibrissa movement in the affected side compared with the normal side. These factors were quantified from + to $+++(-=$ absent $)$.

\section{Statistical study}

Density data were analyzed statistically using analysis of variance and multiple comparisons by the Tukey method (density data transformed into log data), with the accepted significant p-value equal to or less than 0.05 .

\section{RESULTS}

Two rabbits died between the third and fifth postoperative day for unknown reasons. One nerve was excluded from the study due to poor histological quality. The other animals remained healthy during the study period; there was no surgical wound infection or neurondystrophic ulcers.

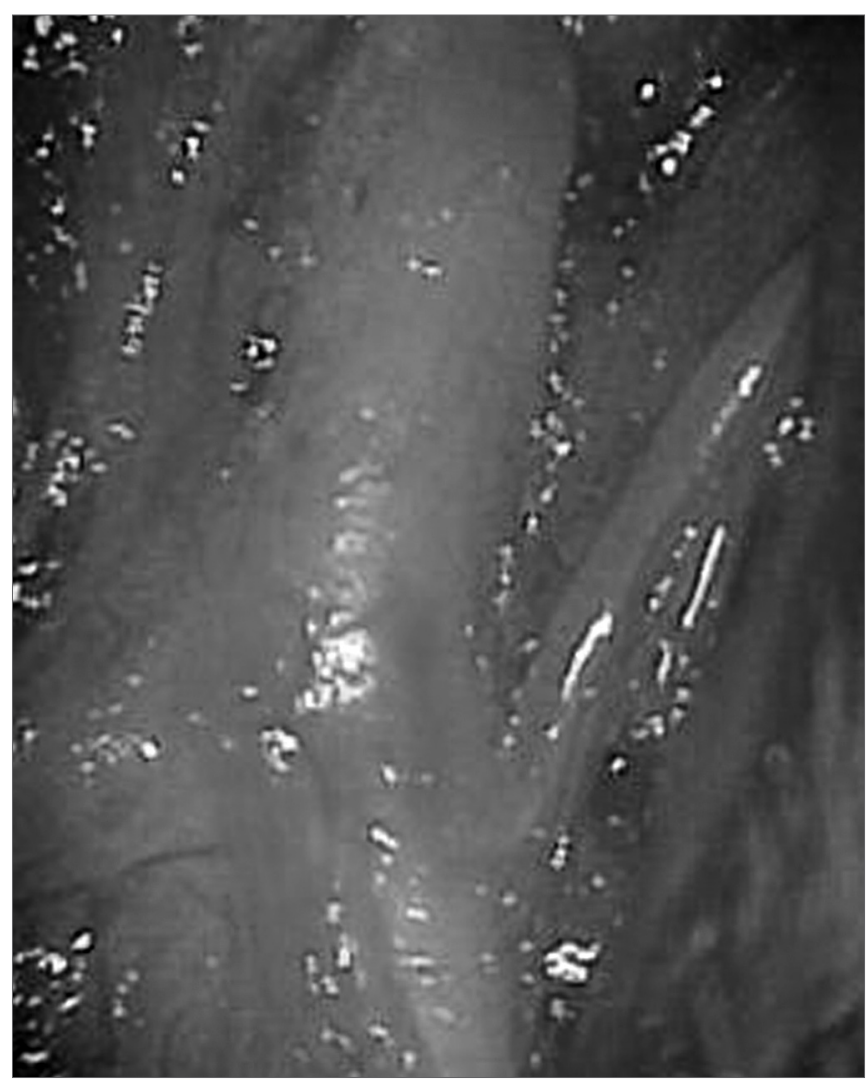

Figure 1b. Left extratemporal facial nerve trunk in the rabbit (mag nified).

\section{Clinical and functional assessment}

Recovery of function parameters are shown schematically on Chart 1.

Chart 1. Recovery of function parameters in the rabbits.

\begin{tabular}{lcccc}
\hline & $\begin{array}{c}\text { facial mus- } \\
\text { cle }\end{array}$ & $\begin{array}{c}\text { vibrissal } \\
\text { movement }\end{array}$ & $\begin{array}{c}\text { blinking } \\
\text { reflex }\end{array}$ & $\begin{array}{c}\text { auricular } \\
\text { ptosis }\end{array}$ \\
\hline 1st week & - & - & - & +++ \\
2nd week & + & + & +++ & ++ \\
5th week & +++ & +++ & +++ & - \\
\hline
\end{tabular}

\section{Qualitative histological analysis}

The nerves were composed of one to five fascicles enveloped by epineuria with spindle shaped cells.

In normal nerves, axons were arranged regularly and had similar diameters. Myelin was dense, with no deterioration. Schwann cells were well distributed, with similarly sized and shaped cell nuclei. The perineurium was a loose connective tissue condensation (Figures 2 and 3).

Injured nerves at two weeks had thinner epineuria and perineuria compared to normal nerves. There were few myelinated axons (mostly in initial stages of myelinization). The myelin sheath was thin and axons had a smaller 


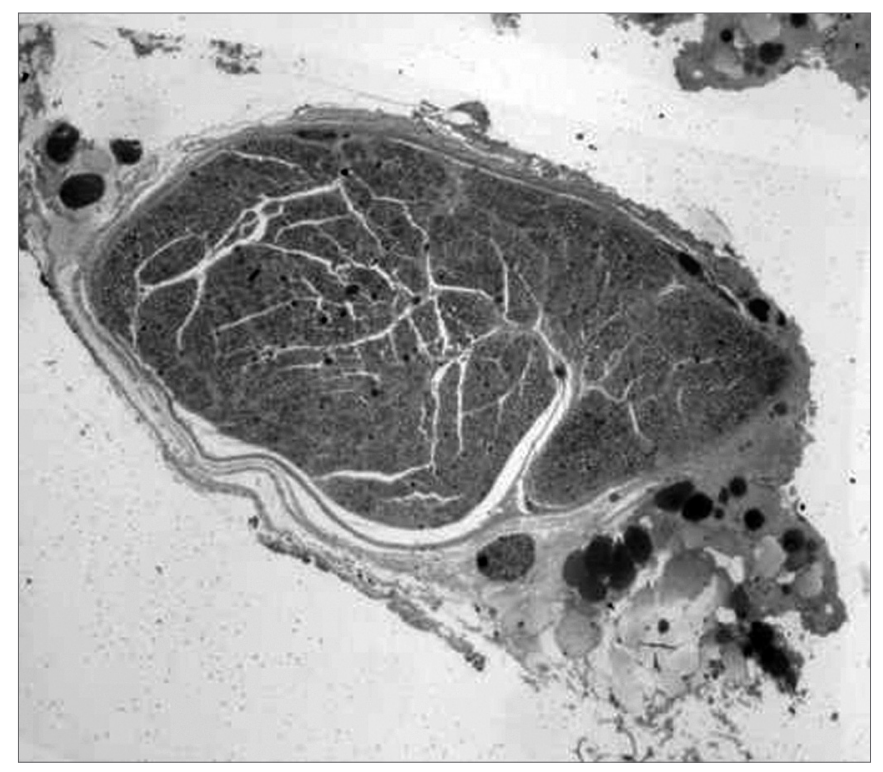

Figure 2. Toluidine blue, $1 \%$ stained histological section of a normal rabbit facial nerve (50X).

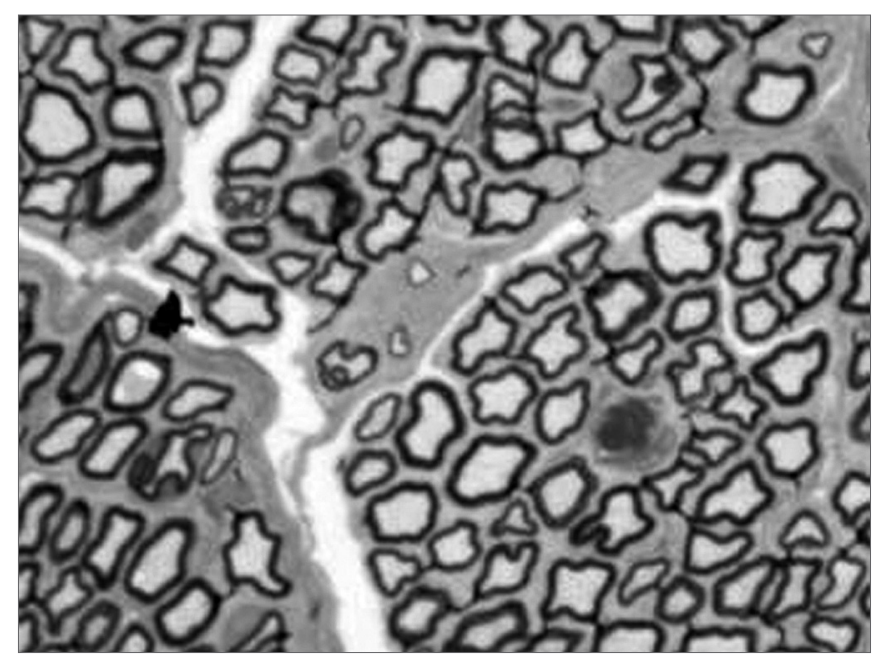

Figure 3. Histological section of a normal rabbit facial nerve (1000X).

diameter compared to those in normal nerves. The stroma was not very dense and there were few collagen fibers. There was moderate neoangiogenesis (Figures 4 and 5).

Injured nerves at four weeks had a larger number of myelinated axons and a variable but generally higher degree of myelinization compared to injured nerves after two weeks. Axon diameters were increased, and myelin sheaths were thicker, but there were still irregularly shaped and variable diameter axons (corresponding to different myelinization stages). There were more Schwann cells, with small and dense nuclei and inconsistent sizes. There were more fibroblasts compared to normal nerves and injured nerves after two weeks. There was intense neoangiogenesis and increased stromal density compa-

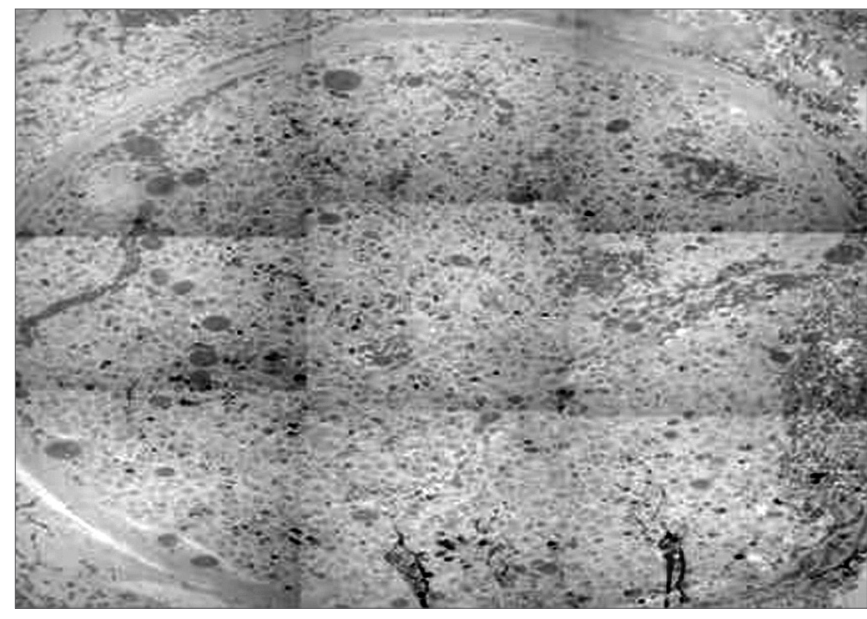

Figure 4. Histological section of the facial nerve at two weeks after injury (50X).

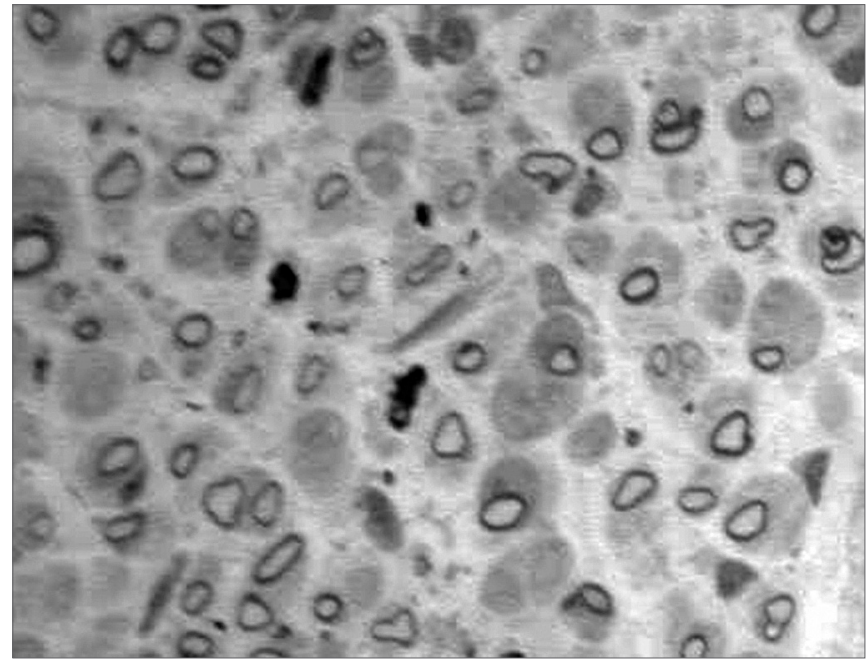

Figure 5. Histological section of the facial nerve at two weeks after injury $(1,000 \mathrm{X})$.

red to injured nerves after two weeks. The epineuria and the perineuria were thicker compared to normal nerves (Figures 6 and 7).

Injured nerves at six weeks had a clear increase in compacted cell elements and collagen fibers within the nerve fascicles, an increased axon diameter, thicker myelin sheaths, more homogeneous axons with near normal contours. There were fewer blood vessels and thinner epineuria compared to injured nerves after four weeks; there were also fewer fibroblasts and Schwann cells (Figures 8 and 9).

\section{Quantitative histological analysis}

Injured nerves at two weeks were excluded from analysis due to low numbers. Study of the AL groups was discontinued due to the difficulty in quantifying axons.

Table 1 presents average and standard deviation 


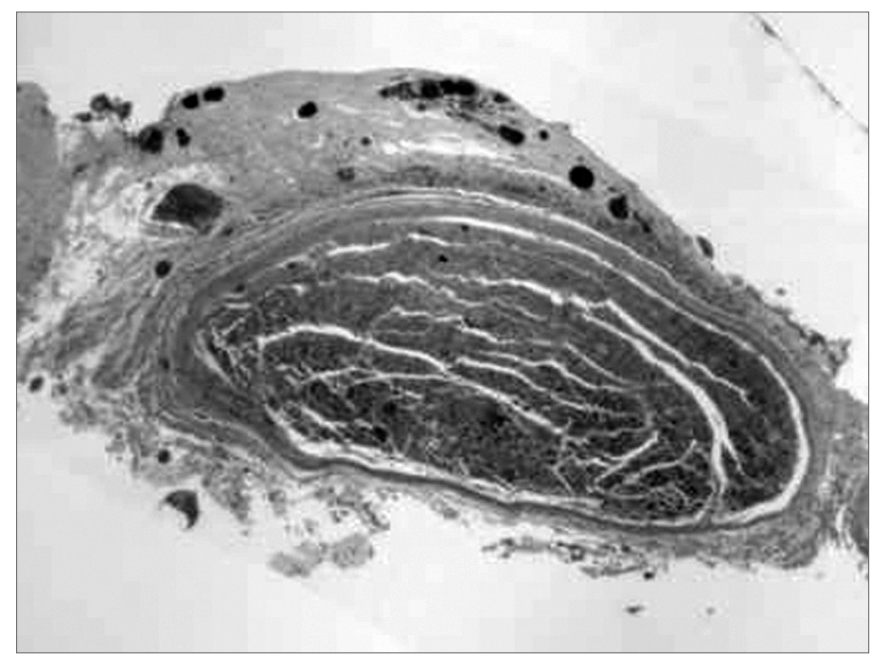

Figure 6. Histological section of the facial nerve at four weeks after injury (50X).

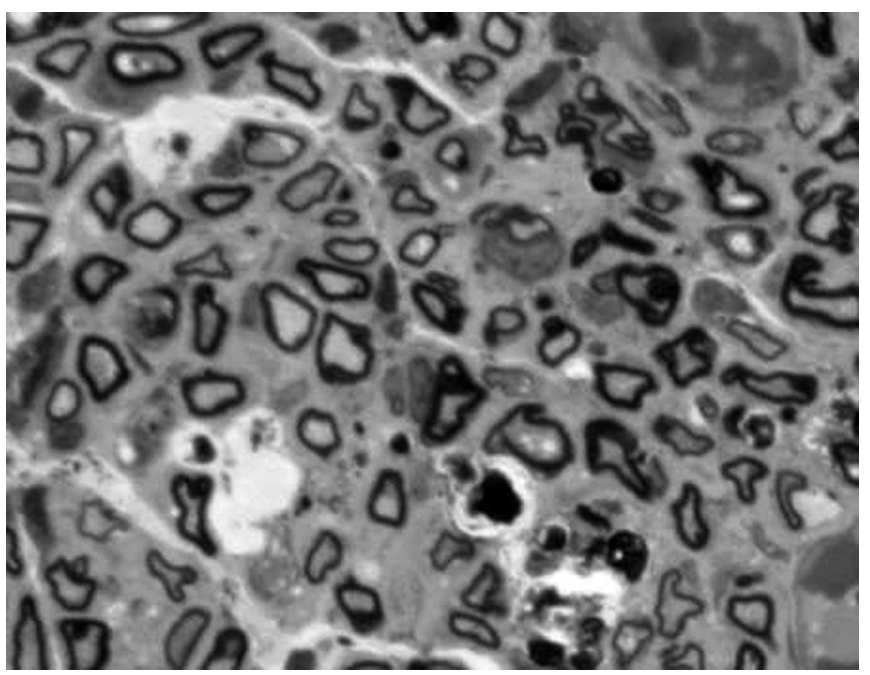

Figure 7. Histological section of the facial nerve at four weeks after injury $(1,000 \mathrm{X})$.

values of the total axon number, the partial axon number, the total nerve cross-sectional area and the partial nerve cross-sectional area for groups N, BL and CL.

Table 1. Morphometric neural data obtained from normal extratemporal facial nerves (group N) and injured extratemporal facial nerves - group BL (4 weeks) and group CL (6 weeks) - from rabbits, showing the average and the standard deviation.

Table 2 and Figure 10 present myelinated axon densities compared to the total nerve area in groups $\mathrm{N}$, $\mathrm{BL}$ and $\mathrm{CL}$.

Normal nerves ( 4 and 6 weeks) presented a higher axon density (axons $/ \mathrm{mm}^{2}$ ) compared to injured nerves. The axon density in injured nerves after six weeks was higher compared axon densities in injured nerves after four weeks. The BL group had $68.88 \%$ of the density of

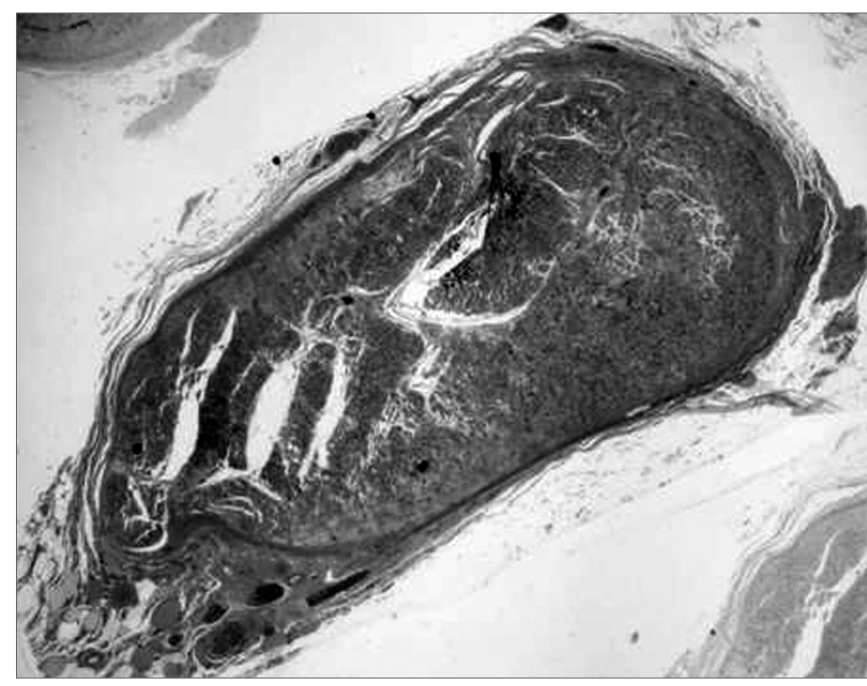

Figure 8. Histological section of the facial nerve at six weeks after injury (50X).

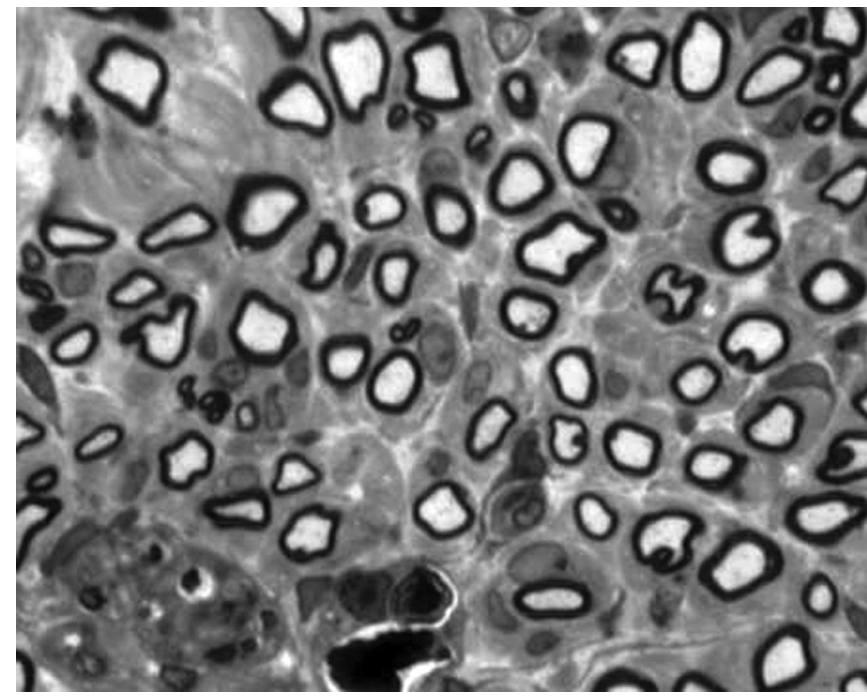

Figure 9. Histological section of the facial nerve at six weeks after injury $(1,000 \mathrm{X})$.

Table 1. Morphometric neural data obtained from normal extratemporal facial nerves (group $\mathrm{N}$ ) and injured extratemporal facial nerves - group BL (4 weeks) and group CL (6 weeks) - from rabbits, showing the average and the standard deviation.

\begin{tabular}{lccc}
\hline Groups & $\mathrm{N}(\mathrm{n}=15)$ & $\mathrm{BL}(\mathrm{n}=8)$ & $\mathrm{CL}(\mathrm{n}=8)$ \\
\hline & $7783,60 \pm$ & $6678,75 \pm$ & $7469,63 \pm$ \\
total axon number & 588,98 & 672,66 & 472,03 \\
partial axon num- & $478,67 \pm$ & $332,13 \pm$ & $415 \pm 28,34$ \\
ber & 28,88 & 21,92 & \\
total area $\left(\mathrm{mm}^{2}\right)$ & $502574 \pm$ & $618298,1 \pm$ & $539598,3 \pm$ \\
& 73747,05 & 62712,68 & 61357,98 \\
partial area $\left(\mathrm{mm}^{2}\right)$ & $22158,8 \pm$ & $21675,25 \pm$ & $25241,5 \pm$ \\
& 2404,35 & 715,96 & 2468,60 \\
\hline
\end{tabular}


Table 2. Myelinated axon density compared to the total extratemporal facial nerve area for normal (group N) and injured nerves (groups BL and $\mathrm{CL}$ ) in rabbits.

\begin{tabular}{ccc}
\hline Nerve & Total density $\left(\right.$ axons $\left./ \mathrm{mm}^{2}\right)$ & $\%$ \\
\hline$N(n=15)$ & $15705,59 \pm 1894,07^{*}$ & 100 \\
$B L(n=8)$ & $10818,55 \pm 630,20^{*}$ & 68,88 \\
$C L(n=8)$ & $13920,36 \pm 914,36^{*}$ & 88,63 \\
\hline
\end{tabular}

*Values are the average and the standard deviation

\section{Figure.10. Total Density}

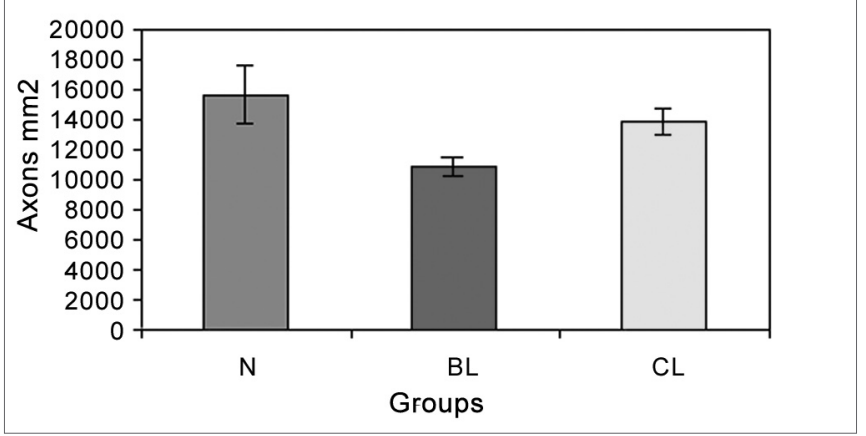

Figure 10. Total myelinated axon density in the different groups $(\mathrm{N}=$ normal; $\mathrm{BL}=$ injured at 4 weeks; $\mathrm{CL}=$ injured at 6 weeks).

the $\mathrm{N}$ group, and the CL group had $88.63 \%$ of the density of the $\mathrm{N}$ group (Table 2). These data were all statistically significant.

Table 3 and Figure 11 present myelinated axon densities compared to the partial area (4 fields at 100X).

The observed graphic pattern was similar when comparing the partial density (axons/mm2). Normal nerves presented a significantly higher density compared to injured nerves. There was, however, no statistical difference between injured nerves after four and six weeks. The BL group had $70.37 \%$ of the density of the $\mathrm{N}$ group, and the CL group had $76.10 \%$ of the density of the $\mathrm{N}$ group (Table 3).

Partial and total densities in normal nerves after four and six weeks were not statistically different. These nerves were placed in the $\mathrm{N}$ group.

Table 3. Myelinated axon density compared to the partial area (4 fields at $1,000 \mathrm{X}$ ) of extratemporal facial nerves in normal (group N) and injured (groups $\mathrm{BL}$ and $\mathrm{CL}$ ) nerves in rabbits.

\begin{tabular}{ccc}
\hline Nerve & Partial density (axons/mm2) & $\%$ \\
\hline$N(n=15)$ & $21800,75 \pm 2339,85^{*}$ & 100 \\
$B L(n=8)$ & $15340,56 \pm 1175,85^{*}$ & 70,37 \\
CL $(n=8)$ & $16589,15 \pm 2069,06^{*}$ & 76,10 \\
\hline
\end{tabular}

* Values are the average and the standard deviation

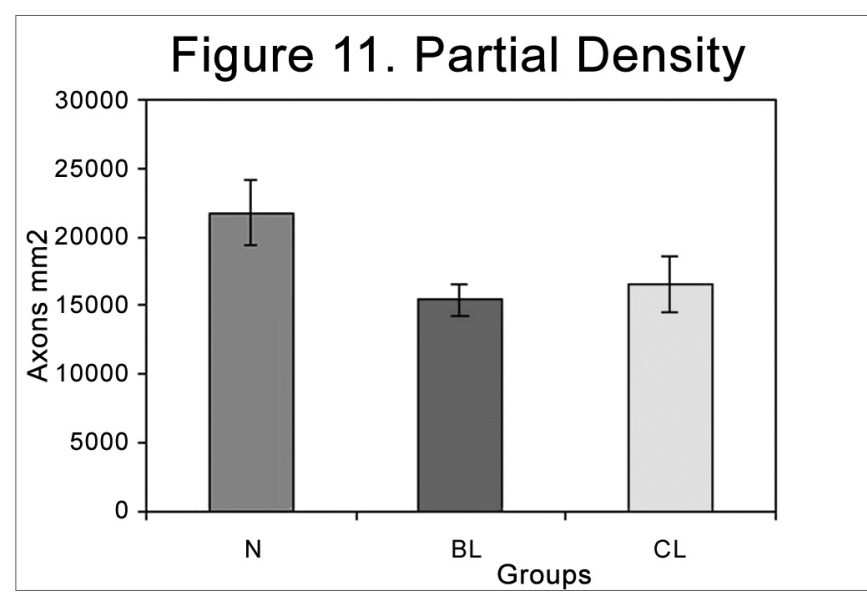

Figure 11. Partial myelinated axon density in the different groups ( $\mathrm{N}=$ normal; $\mathrm{BL}=$ injured at 4 weeks; $\mathrm{CL}=$ injured at 6 weeks).

\section{DISCUSSION}

Rabbits as experimental animals were used based on previous studies that found marked chromatolysis and complete neuron recovery after few weeks following nerve crush injuries, in contrast with mice, which presented atypical post-traumatic axon reactions. ${ }^{21,22}$ The anatomical features of the rabbit facial nerve are similar to those of the human facial nerve. ${ }^{23,24}$

The facial nerve trunk was chosen as the injury site since this nerve has comparatively fewer anatomical variations in its branches ${ }^{17}$ and is close to the nourishing neuron, therefore having an increased regeneration rate compared to distal portions of the nerve. ${ }^{25}$ Clinical nerve function can also be assessed without sophisticated devices.

In our study the recovery of face movement function signs occurred in the first few weeks, which agrees with other authors using similar methods..$^{22,18,20}$

The compression injury mechanism used in our study was previously established by Cai et al. (1998), a method that creates a grade II injury according to Sunderland's classification (1978). ${ }^{27}$ The sectioning and suturing method was avoided due to interferences from possible surgical technique differences and a large number of syncinesias. ${ }^{26}$

Histological analysis counting the number of myelinated axons is a widely used method in international literature for rabbits, rats and hamsters, and is considered by most authors as an objective method to study neural regeneration. ${ }^{16-18,28,29}$ However, some authors define a constant neural area ${ }^{17,18,28}$ whereas other authors only compare the total nerve axon number. ${ }^{16,19}$

In this study we compared the axon number density compared to the total nerve area and a defined partial neural area. There is no published report counting the number of axons in the facial nerve trunk in rabbits, and 
there are no parameters for the observed total numbers. The comparative analysis between total and partial axon counts shows that the total axon number was more reliable than the partial axon number in injured nerves after four and six weeks. The partial count is undoubtedly more practical, although one should bear in mind that analysis could be made of a less affected region, which would bias the results.

Cai et al. (1998)5 did a qualitative nerve analysis to histologically compare different types of nerve injury. This analysis detected only the general tissue aspect looking at the preservation of anatomical structures and the degree of the inflammatory process following injury, with no quantification of degeneration and regeneration.

In our study we associated the abovementioned method to quantitative analysis. Therefore, we obtained not only the quality of regenerated nerve tissue but also a precise quantification of regeneration in time.

Based on a previous study that inferred the relationship between myelinated and amyelinated fibers according to the duration of injury, we decided to verify the intervals in the regeneration process, at its approximate beginning (two weeks) and in two periods of progression (four and six weeks). ${ }^{17}$

After six weeks almost 90\% of the injured nerve axons were myelinated compared to normal nerves (almost the full regeneration process). This finding is important for studies on drugs that affect nerve regeneration. We know that in this model the regeneration process begins at approximately two weeks, following significant degeneration; at four weeks there is partial regeneration and at six weeks there is almost total regeneration. Therefore, when using a systemic drug, it will be possible to establish in which period the drug will operate.

\section{CONCLUSIONS}

After compression injury of the extratemporal facial nerve trunk in rabbits, we observed loss of facial muscle activity, followed by partial recovery at two weeks and complete recovery after five weeks from injury.

Qualitative histological analysis of the extratemporal facial nerve trunk revealed an axon degeneration pattern with an intense tissue inflammatory process at two weeks following injury. At four weeks from injury, there were evident signs of nerve tissue regeneration, which became almost complete at six weeks after nerve injury. Quantitative histological analysis disclosed a higher total cross-sectional area in normal nerves compared to injured nerves, and the injured nerve density at six weeks after injury was higher than the injured nerve density at four weeks.

Normal nerves presented a significantly higher partial cross-sectional axon density compared to injured nerves. There was, however, no statistical difference between injured nerves at four and six weeks following injury. Total nerve cross-sectional axon density is a more reliable analytical method to study nerve regeneration compared with the partial axon density in injuries of the extratemporal facial nerve trunk in rabbits.

\section{REFERENCES}

1. Bento RF, Miniti A, Ruocco JR. Traumatic peripheral facial palsy. In Portmann M: Facial Nerve. Paris 1985;299-303.

2. Conly J. New concepts in facial palsy. In: Portmann M: International Symposium On The Facial Nerve, 5. Proceedings. New York: Masson; 1985. p.564-66

3. May M. Differential diagnosis by history, physical findings, and laboratory results. In: ___ The Facial Nerve. New York, Thieme Inc 1986b; 81-219.

4. Labella T. Etiology and pathogens of facial palsy. In: Kugler \& Ghedini - World Congress Of Otorhinolaryngology, Head And Neck Surgery, 14. Proceedings. Amsterdam: Sacristian 1990; 655-7.

5. Cai Z, Yu G, Ma D, Tan J, Yang Z, Zhang X. Experimental studies on traumatic facial nerve injury. J Laryngol Otol 1998;112:243-7.

6. Seckel BR, Chiu TN, Nyilas E, Sidman Rl. Nerve regeneration through synthetic biodegradable nerve guides: regulation by the target organ. Plast Reconstr Surg 1984;74:173-81.

7. Buttermeyer R, Rao U, Jones NF. Peripheral nerve allograft transplantation with FK 506 functional, histological, and immunological results before and after discontinuation of immunosuppresion. Ann Plast Surg 1995; 35:396-401.

8. De Medinaceli L \& Seaber AV. Experimental nerve reconnection importance of initial repair. Microsurg 1989;10:56-70.

9. Wang MS, Zeleny-Pooley M, Gold BG. Comparative dose-dependence study of FK 506 and cyclosporine a on the rate of axonal regeneration in the rat sciatic nerve. J Pharmacol Exp Ther 1997; 282:1084-8.

10. Costa MP. Emprego do tubo de ácido poliglicólico como substituto de enxerto de nervo: estudo experimental em ratos. São Paulo, 1998 (Tese - Mestrado - Universidade de São Paulo).

11. Mohammad J, Shenaq J, Rabinovsky E, Shenaq S. Modulation of peripheral nerve regeneration: a tissue-engineering approach. The role of amnion tube nerve conduit across a 1- centimeter nerve gap. Plast Reconstr Surg 2000;105:660-3.

12. Costa MP. Tubo de ácido poliglicólico e FK506 na regeneração de nervos periféricos: estudo experimental em ratos. São Paulo, 2001 (Tese - Doutorado - Universidade de São Paulo).

13. McGovern FH. The return of function after damage to the facial nerve. Eye Ear Nose Throat Mon 1970;49:451-4.

14. Mccoy EG \& Boyle WF. Reinnervation of the nerve resection. Laryngoscope 1971;81:1-7.

15. Labelle Jl \& Allen DE. The peripheral nerve repair. A review. J Maine Med Assoc 1972; 63:164-6.

16. Szal GJ \& Miller T. Surgical repair of facial nerve branches. An analysis of different sheathing and suturing techniques. Arch Otolaryngol 1975;101:160-5

17. Spector JG, Lee P, Derby A, Frierdich GE, Neises G, Roufa DG. Rabbit facial nerve regeneration in NGF-containing silastic tubes. Laryngoscope 1993May;103:548-58

18. Spector JG, Lee P, Derby A. Rabbit facial nerve regeneration in autologous nerve grafts after antecedent injury. Laryngoscope 2000;110:6607.

19. Vasconcelos BCE \& Gay-Escoda C. Facial nerve repair with expanded plytetrafluoroethylene and collagen conduits: an experimental study in the rabbit. J Oral Maxillofac Surg 2000;58:1257-62.

20. Jones KJ. Recovery from facial paralysis following crush injury of the facial nerve in hamsters: differential effects of gender and androgen exposure. Exp Neurol 1993;121:133-8.

21. Torvik A. Phagocytosis of nerve cells during retrograde degeneration. An electron microscopic study. J Neuropath Exp Neurol 1972;31:132.

22. Torvik A \& Sã-Reide AJ. Nerve cell regeneration after axon lesions 
in newborn rabbits. J Neuropath Exp Neurol 1972;31:683.

23. Kozma C, Macklin W, Cummings LM, Mauer R. Anatomy, physiology and biochemistry of the rabbit. In: Weisbroth SH, Flatt RE, Kraus AL: The biology of the laboratory rabbit. Academic 1974;50-5.

24. Shek JW, Wen GY, Wismewski HM. Atlas of the rabbit brain and spinal cord. Karger 1986;3-8.

25. Colli BO. Aspectos gerais das lesões traumáticas agudas nos nervos periféricos. Arq Bras Neurocirurg 1993;12:171-200.

26. Ochi M, Noda M, Nakamitsu K, Deie M, Ikuta Y, Maki Y, Awaya A. Promotion of sciatic nerve regeneration in rats by a new neurotrophic pyrimidine derivative MS-430. Gen Pharmac 1995;26:59-64.
27. Sunderland S. Nerve and nerve injuries, 2 ed. London, ChurchillLivingston 1978;88-9, 96-97, 133.

28. Lewin Sl, Utley DS, Cheng ET, Verity NA, Terris DJ. Simultaneous treatment with BDNF and CNTF after peripheral nerve transection and repair enhances rate of functional recovery compared with BDNF treatment alone. Laryngoscope 1997;107:992-9.

29. Neherer-Tairych GV, Kamolz Ml, Deutinger M, Stã-Hr HG, Frey M. The influence of the donor nerve on the function and morphology of a mimic muscle after cross innervation: an experimental study in rabbits. Br J Plast Surg 2000;53:669-75. 